
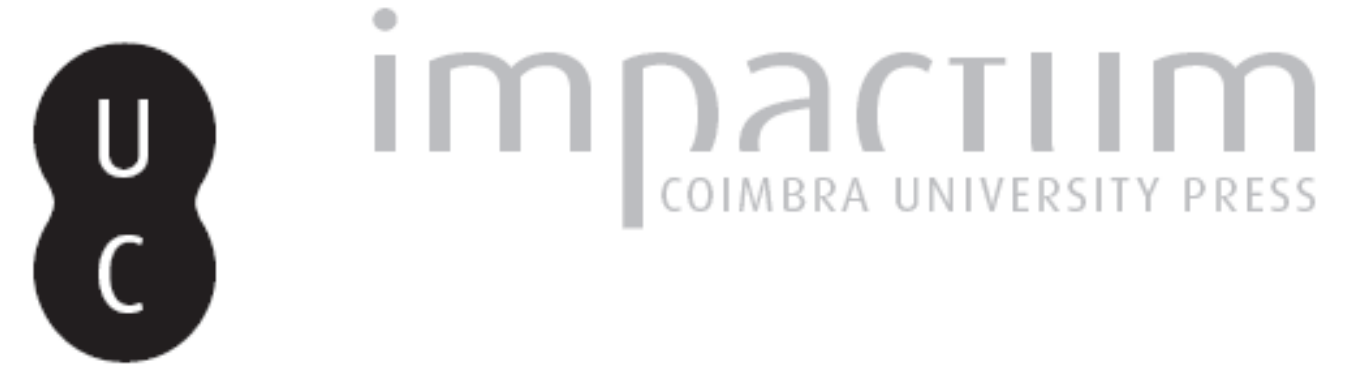

\title{
Cidade: o sonho de nero, o desenho, o comércio tradicional e outras provocações expressas de forma desordenada
}

\author{
Autor(es): Rossa, Walter \\ Publicado por: Editorial do Departamento de Arquitectura \\ URL \\ persistente: \\ URI:http://hdl.handle.net/10316.2/37447 \\ DOI: \\ DOI:http://dx.doi.org/10.14195/0874-6168_3_2
}

Accessed : $\quad$ 26-Apr-2023 15:46:22

A navegação consulta e descarregamento dos títulos inseridos nas Bibliotecas Digitais UC Digitalis, UC Pombalina e UC Impactum, pressupõem a aceitação plena e sem reservas dos Termos e Condições de Uso destas Bibliotecas Digitais, disponíveis em https://digitalis.uc.pt/pt-pt/termos.

Conforme exposto nos referidos Termos e Condições de Uso, o descarregamento de títulos de acesso restrito requer uma licença válida de autorização devendo o utilizador aceder ao(s) documento(s) a partir de um endereço de IP da instituição detentora da supramencionada licença.

Ao utilizador é apenas permitido o descarregamento para uso pessoal, pelo que o emprego do(s) título(s) descarregado(s) para outro fim, designadamente comercial, carece de autorização do respetivo autor ou editor da obra.

Na medida em que todas as obras da UC Digitalis se encontram protegidas pelo Código do Direito de Autor e Direitos Conexos e demais legislação aplicável, toda a cópia, parcial ou total, deste documento, nos casos em que é legalmente admitida, deverá conter ou fazer-se acompanhar por este aviso.

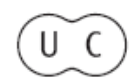




\section{ecdj $\quad z$}

fctuc|departamento de arquitectura

novos mapas para velhas cidades

guido giangregorio / walter rossa

rui lobo | álvaro domingues / nuno grande

joão paulo cardielos / josé antónio bandeirinha

workshop internacional de arquitectura

coimbra: um novo mapa [16 a 25 de novembro]

projectos

manuel graça dias margueira

manuel fernandes de sá marginal do douro antónio belém lima vila real

editores jorge figueira + nuno grande 
[cidade: o sonho de nero, o desenho, o comércio tradicional e outras provocações expressas de forma desordenada]

walter rossa

Não é novidade para ninguém o facto de a cidade ser o principal objecto do exercício do poder. Digo objecto e não palco ou cenário (como é mais frequente), porque o poder só se exibe quando é exercido e por tal razão acaba por lhe ser essencial a matéria de acção e a sua maior ou menor ductibilidade. Nesse âmbito o espaço só é relevante enquanto parte do todo e não apenas como moldura ou suporte físico do acto.

> Falo, obviamente, da cidade no seu todo cultural e civilizacional e não pela perspectiva habitualmente atribuida aos arquitectos, que de facto tendem a (simular) confundir (ou a hiper-valorizar) uma pequena série de coisas com o todo. Mas não são, de forma alguma, a excepção.

O problema é que, sobre a superfície do planeta, jamais alguém logrará deter a necessária capacidade omnisciente para ver a cidade na sua totalidade, ou seja, sem um filtro de deformação pessoal e profissional. Ainda bem! Boa, má ou assim-assim todos temos uma personalidade... e todos temos direitos de cidadania... e o dever de a compartilhar... (que pena!) Claro que "em automático" organizamos essa partilha por forma a abdicar o menos possível do quinhão em que somos especialistas ou, pelos menos, para o qual fomos treinados. 
> Talvez por facilidade, por entender que o estudo das vanguardas dá o pulsar do futuro ou por mero gozo, a literatura especializada na cidade tende a expor e dissertar sobre o meio demiúrgico ou pró-totalitário a que pertence, seja ele o do Urbanismo, o da Economia, o da Sociologia ou outros, sob a forma de estudos, planos, projectos, propostas, promessas, intenções, impressões, sensações, desilusões, etc. E não é por acaso que cada uma dessas áreas do saber tem um apêndice de história.

É que, para além da legitimação, por vezes interessa-Ihe a História para justificar opções que hipoteticamente visam evitar a repetição de erros, acção verdadeiramente desnecessária se linear, porque na realidade a história nunca se repete e é só aquilo que nós hoje pensamos sobre as justificações do presente.

> Mas é grave que nem sempre se leiam na História as matrizes e tendências da evolução através de uma espécie de método a que se poderia chamar a ecologia da civilização ou do processo histórico. Grave é quando se considera o tecido urbano do passado como meramente histórico, ou seja, apenas como um testemunho e não como uma realidade, opção ou variável do presente. O problema é que por mais esforço que se faça nunca se vive como no passado e o restauro, a conservação ou a reabilitação só fazem sentido quando a "matéria de facto" conserva algo de significativo nos referenciais comunitários da identidade.

> No útil, desejável e inevitável estado de coisas que buliçosamente jaz por trás do que acaba de ser escrito, tem tido muito pouca visibilidade e estudo o fogoso exercício de poder desenvolvido pelo conjunto dos cidadãos. Mas o espaço que habitamos é, em boa medida, consequência dessa acção, nomeadamente na sua mais específica materialidade o urbanismo - assunto que obviamente aqui mais nos interessa. Igual sucede com as permanentes e irritantes "alterações ao projecto" que os eruditos da cidade vêm ser introduzidas às utopias totalitárias - passo o circunlóquio - laboriosamente e sabiamente arquitectadas pelos especialistas sob a forma de planos. É que da Urbanística ao Urbanismo vai a distância a que corresponde a intervenção da sociedade como promotora do acto e processo de Urbanização.

> Sendo um claro resultado de uma sensação genérica de desenvolvimento, não deixa de ser interessante o gradual crescendo de interesse que a opinião pública - leia-se no sentido de "opinião de mais pessoas que o habitual, alimentada em espiral e expressa em público" e não no abusivo sentido de consenso - tem vindo a demonstrar pelas questões relacionadas com o meio ambiente urbano e, em especial, pelo urbanismo. Ou seja, aquilo que os arquitectos um dia almejaram poder capitanear - talvez porque os outros "não entendessem" - é hoje objecto de interesse de parte considerável da sociedade que também assim pretende exercer os seus direitos de cidadania, ou melhor, o seu poder. Será esse finalmente o trilho para um qualificado Urbanismo Democrático? 
> Esse comportamento nem sempre é exercido com vista à defesa de interesses comuns, o que de um ponto de vista "antropológico" até nem tem mal. A moda, a sedimentação de novas matrizes de vida, a comunicação, a uniformização global levam a que os desejos individuais de diferença surjam de forma padronizada. Assim se constituem autênticas opções de conjunto, por mais individualizado e exclusivo que seja o desígnio de cada um ou mais distante e bizarro o modelo de inspiração. O individualismo não deixa de produzir efeitos comuns e de grupo, verdadeiros componentes de padrões culturais da sociedade de que, por muitas vezes, se quer destacar. Por outras palavras, o individualismo é 'vulgar' e um motor da sociedade, em especial quando na generalidade temos vindo a alinhar pela liberalização global, ou seja, pela desenfreada massificação do individualismo.

> Mas o que pode isso interessar à análise dos processos urbanísticos? Em minha opinião uma e outra coisa correspondem-se. A resolução de muitos dos problemas de incompatibilidade demonstrada entre a Urbanística mais refinada/erudita e os processos urbanos resultará, quiçá, da construção desse entendimento. A globalização dos costumes e das condutas leva as comunidades a óbvios problemas de evolução da identidade e esta a ainda mais evidentes desalinhos na identificação com os espaços de referência.

O falhanço do "estilo internacional" em arquitectura parece que virá a ser compensado pelos "estilos internacionais" no que diz respeito à urbe. Persistirão por certo imagens únicas e características locativas específicas, mas no seu todo os comportamentos tendem ao estereótipo. É um facto civilizacional e, se assim for, incontornável, mas talvez seja susceptível de qualificação.

> Tudo quanto aqui exprimo diz respeito a uma cidade em evolução e pouco tem em linha de conta a feliz inevitabilidade e eficácia de focos de resistência. Os modelos urbanos actuais, com maior ou menor expressão e autenticidade, serão preservados e re-interpretados em muitos espaços do planeta. Como sempre, a evolução permanecerá desigual no espaço e no tempo para qualquer ponto considerado. Mas desta feita interessa-nos inquirir alguns aspectos de uma tendência da vanguarda dos processos urbanos.

> No mundo ocidental durante séculos a evolução foi marcada pelas dinâmicas europeias, cabendo aos latinos a preponderância no que diz respeito à própria consolidação e evolução do conceito de urbanidade. A cidade como tradicionalmente a entendemos é, fundamentalmente, uma criação mediterrânica. Independentemente do peso económico do mundo rural, em toda a História anterior ao fim do Antigo Regime sempre foi a cidade o referente ecdj 0s0.021 civilizacional da sociedade. E assim continuou e, de certa forma, continua a ser, embora a emergência de novos equilíbrios proporcionados pela maioridade das nações do Novo Mundo tenha introduzido fortes alterações. Quanto mais não seja porque entre elas têm crescente desempenho hegemónico algumas cuja origem colonial e de soberania teve vincado carácter rural, como é o caso dos próprios Estados Unidos. O crescimento do Brasil poderia vir a 
ser a excepção, se entretanto a sua própria evolução no sentido da aproximação aos modelos urbanos norte-americanos cessasse. Mas porquê e para quê?

> Por entre os desafios da contemporanidade vão de facto ganhando destaque os da cidade, até porque nos aproximamos do "pleno" da urbanidade. Parte considerável dos grandes debates actuais centram-se sobre temas urbanos, sendo relevante a importância do espaço como um dos elementos congregadores daquele conceito. Se em História do Urbanismo a maior parte dos casos de referencia correspondem a realizações mais ou menos corporizadas por indivíduos ou pequenas oligarquias, o inevitável alastrar de uma mediana democracia fará com que esta disciplina gradualmente passe a integrar as resultantes da acção de grupos cada vez mais alargados, num progressivo crescimento dos estudos pluridisciplinares.

Cada vez mais o desenho sem a Sociologia, a Economia e o Direito (por exemplo) não produz urbanismo e não é um objectivo em sí. É por isso que os indicadores e debates urbanos mais simples têm uma importância fulcral.

> Num texto com estas características seria ainda mais pretensioso fingir abordar de forma conveniente sequer um dos temas desses debates. Mas é possivel prosseguir na linha de uma razoável coerência de contradições. Algumas acções recentes levaram-me a alinhar de forma simples umas escassas considerações banais que, no conjunto, me parecem configurar certas tendências urbanas susceptíveis de a médio prazo influenciarem o desígnio urbano e até, porque não, o urbanismo de que usufruímos.

> Um dos aspectos que parece de mais simples abordagem é a questão da mobilidade. Se assim o pretendermos, numa ou outra situação, num ou noutro meio mais elitista, por entre ambientes mais ou menos 'eco-esquizofrénicos', poderemos encontrar indícios de um futuro com menos automóveis no meio ambiente urbano, de quase integral recurso a transportes públicos ou a habilidades equilibristas (trotinetes, bicicletas, patins), mas a maioria da população, mesmo vigorosamente fustigada por acusações de exibicionismo de status recém adquirido, recusar-se-à sempre a chegar ao emprego esbaforida, descomposta e odorosa, para não dizer o pior. Numa caricatura, não me parece provável uma evolução que permita e dê meios às pessoas para se "arranjarem" depois de chegar ao emprego com os trajes menores com que largaram o leito e os filhos num infantário ou escola.

> Na realidade esquecemo-nos que os sacrifícios de vanguarda são coisa para pessoas e comunidades que podem suportar o custo de quem lhes trate dos problemas comezinhos da... retaguarda. Sejamos realistas, jamais um país pobre poderá economica e socialmente suportar o ónus de abandonar o usofruto dos pequenos "luxos" recém conquistados. Seja qual for a solução tecnológica, no "terceiro" mundo (que é monstruosamente maior do que isso), mas também no ínfimo "primeiro", um meio confortável de transporte individual será cada vez 
mais preferido pelas massas, ainda que disfarçado pela individualidade das marcas, modelos, cores e adaptações.

> Por mim, e também sem qualquer esperança, o automóvel na cidade (para a qual foi feito) preocupa-me infinitamente menos do que no meio rural (no qual até faz todo o sentido). Aliás, de certa forma o automóvel é uma forma de compensação entre ambos os pólos, ou melhor, tem vindo a cumprir um importante papel de diluição.

A verdade é que entre nós já quase não há meio rural, mas tão só muita ruralidade. Temos vindo a caminhar para uma mescla de sinais e formas de vida, das quais uma das mais recentes e insignificantes é a sistemática utilização citadina de veículos todo-o-terreno.

> Numa crescente fobia pela ruralidade, o "urbanita de todo-o-terreno" estraga sistematicamente os outrora pacatos fins-de-semana dos rurais - uma espécie em vias de extinção - e busca na cidade a forma de viver o sonho de Nero, de preferência num ambiente fechado com via-rápida à porta, onde os laços de vizinhança jamais corresponderão a uma rural comunhão de vidas, mas tão só a um igual compartilhar de status. Como a Nero - que, como sabemos, destruíu o centro de Roma para ali erguer um idílico palácio que, entre outras "miudezas" menos exemplares, foi dotado com um lago artificial - pouco importa a destruição do espaço público e do sentido tradicional de cidade, se a individualidade pretensamente rural se sublimar numa estrutura urbana apenas vocacionada a conectar as idiosincresias de cada um e os equipamentos de grupo. Pior é quando se interpreta o campo ou as áreas ditas de reserva como espaços de fruição individual, dignos para si, mas nem sequer para uma comunidade de "urbanitas de condomínio fechado" ... ou "de todo-o-terreno".

> De facto pouco adiantam as zonas de reserva, seja ela ecológica, natural, integral, indígena, etc. Se verdadeiramente alguém quisesse proteger ou reservar algo dos "nefastos" urbanitas bastaria promover as respectivas áreas como livres de internet, telemóvel, televisão, etc. Desde logo os raids se extinguiriam nesse meio adverso à condição humana, onde na realidade $\mathrm{o}$ ar assim se tornaria verdadeiramente irrespirável para qualquer humano realmente civilizado. Mas um dia tudo será cidade numa ruralidade sofisticada e assim todas as formas de vida sobreviverão. Afinal, segundo um enfoque meramente urbano e humano, formas de vida e formas de viver são apenas variações semânticas de uma mesma realidade.

> No meio ambiente urbano, a procura de originalidade tem algumas excepções formais. Uma delas é a súbita nostalgia por uma realidade que à escala da História é efémera, mas rotulada de 'tradicional': uma determinada forma de comércio.

O comércio tradicional, conforme é entendido e defendido, é uma realidade recente, quiçá com um século de existência, e de facto faz cada vez menos sentido face ao pragmatismo 
e racionalismo de uma sociedade moderna. Não é por acaso que cada vez que se tenta implantar numa nova área, mais cedo ou mais tarde acaba por se consolidar como pólo de estabelecimentos de restauração e animação lúdica. Afinal não será o grande e "odiado" centro comercial a emulação mais fiel da velha loja da aldeia onde se vendia tudo o que era necessário à comunidade? A responsabilidade pela mudança de escala é nossa, pois cada vez mais não nos contentamos apenas com o que vemos.

> Gradualmente as pessoas vão-se recusando a sair de casa para ir fazer as suas deambulações consumistas em percursos desprotegidos e mal equipados, embora um dos problemas principais talvez seja a falta de identificação entre as imagens do bombardeamento publicitário dos media e os códigos das lojas de rua. Hoje em dia tendemos a sentir-nos perdidos e desconfiados quando não reconhecemos "a marca", pois julgamos saber aquilo que queremos.

Produtos genuínos, isto é, sem certificado de origem controlada? Isso só "na terra" ou em lojas de amizades recentes, essas sim "certificadas". Certo, o logro é total, mas faz parte do encanto de ir às compras.

> A dura realidade é que as principais instituições que promovem o rejuvenescimento do comércio dito tradicional, no fundo são as mesmas que quase mensalmente analisam avidamente as últimas estatísticas sobre o crescimento do "comércio on-line" e estudam formas de the dar maior segurança e credibilidade. São ainda as mesmas que nos arranjam forma de pôr tudo em casa, embora o saudoso pão fresco pendurado na porta pela madrugada não tenha ainda regressado. Essa sim deveria ser considerada uma instituição a "tradicionalizar" e proteger.

O logro é, de facto, total, mas de certa forma faz sentido. "Sair" para deambular entre os dejectos dos "pets" urbanitas e voltar esfalfado? E porque não "sair" apenas para me divertir? Perdida a relação habitacional de rua e a referida forma efémera de comércio, parece ser esse o verdadeiro e afunilado futuro do espaço público tradicional, ou seja, o não exclusivamente viário ou o do comércio encerrado em feéricos malls comerciais.

Entre as zonas de lazer de referencial arquitectónico (uns restaurantódromos e baródromos com ou sem "docas" e "ginásios de fitness") e paisagístico (os parques, complexos desportivos e outras formas de tortura física ao ar livre) desenrolar-se-ão nas próximas décadas os episódios da vida urbana não exclusivamente doméstica e laboral? Por exemplo, a massificação diurna das praias dará lugar a arnados de urbanidade nocturna?

Por outro lado tem-me causado grande estranheza as crescentes decisões de iluminar os jardins e parques urbanos em nome da segurança. Mas porque é que as pessoas hão-de querer ir para um parque à noite a não ser para correr (com) determinados riscos?

> No fundo as questóes da mobilidade, do comércio e do lazer, entre outros, têm-se vindo a constituir na moldura que enquadra o "problema do centro". 
Uma cidade como a que aqui tenho caricaturado terá fundamentalmente características de subúrbio, o que até pode nem ser mau se recorrermos a exemplos de subúrbios qualificados, que também os há e em número crescente. Obviamente estas questões inserem-se no quadro mais vasto (em extensão e temática) da tendência conurbadora ou megalopolitana de zonas como, por exemplo, as faixas litorais de muitos territórios, mas não ilude a arreigada necessidade cultural de um centro de identidade, uma referência de centralidade não necessariamente histórica, mas congregadora de um necessário e ainda que virtual espírito de comunidade, ou seja, de História.

\section{> A luta por uma plenitude de direitos e pela qualidade de vida tem vindo a desaguar no crescimento de um sector da economia e até de um certo estilo de vida.}

Todos sabemos como a era industrial parece estar a ser rendida por uma idade de serviços. Até parece que o anátema dos desequilibrios ambientais e psíquicos motivados pela indústria se está a deixar substituir pelo stress da escolha perante a colossal variedade das tentações. A automatização electrónica não nos libertou o tempo extra para o lazer como esperávamos, mas tão só a oportunidade (e a exigência) de fazermos mais e, a par com a mobilidade física, deu-nos um acesso virtual a tanta coisa que continua realmente inacessível.

$\mathrm{Na}$ fobia totalitária pelo bem-estar continuamos, como sempre, a compensá-lo com novas formas de mal-estar. É o sentido da evolução e da Vida.

> Foi sempre com Arquitectura que se construiu a materialidade visual da cidade. Alguma monumental, e de referência, mas a maioritária sendo comum ou até medíocre. É a realidade triste, mas tão inquestionável quanto a necessidade de continuar a lutar pela sua qualificação. E se hoje globalmente se vai invertendo a tendência de a arquitectura ser feita por "não-credenciados", sabemos como isso é apenas uma garantia genérica de qualidade (ordinária?) e uma novidade no contexto geral da História.

Mas estaremos atentos para a necessidade de garantir a qualidade do desenho das "cidades virtuais" que em jogos, mas não só, vão formando o imaginário urbanístico das futuras gerações activas? Isto é, estão os arquitectos aptos e com apetite para desenhar a imaterialidade urbanistica, a imagem da cidade virtual? E depois, quem the confere a patine do uso? Ou será que não a deve ter, constituindo-se a cidade virtual na tão utópica oportunidade de se construir e viver a cidade ideal?

É que, conduzidos por um predominante sentido elitista da crítica, tendemos a desligar a qualidade global (por isso essencialmente urbana) da Arquitectura, da análise específica do objecto. Nesse âmbito o utente ou é um "arquitectófilo" ou pouco conta, sendo insconscientemente constituído como a patine do edifício, um "térmita" que, tal como os intervenientes no processo da construção, tudo fará para lhe retirar a graça do projecto.

Mas um projecto não é Arquitectura. Discuta-se pois a sua qualidade quando se acabou de 
concretizar, uma vez que assim é mais fácil de analisar, mas discuta-se também em sede de projecto o seu contributo social, ou seja, a sua urbanidade.

Porém uma fundamentada crítica à arquitectura só é possível algum tempo depois, quando cumprido o tempo suficiente para a sua entrada em pleno funcionamento $e$ integração no quotidiano. Será uma crítica também feita pelo usufruto, quando já adquiriu a tal patine constituida pelos seus ocupantes, quando deixou de ser uma surpresa na cidade apenas pela sua novidade e manteve a sua individualidade no concerto do espaço urbano.

Nessa re-aproximação da Arquitectura à cidade, e fazendo dela um preponderante instrumento da Urbanística e do Ordenamento do Território, devemos ter em linha de conta que, mais do que no universo dos edifícios, não há cidade alguma que tenha sido concretizada como foi concebida. As eventualmente irritantes "alterações ao projecto" efectuadas pelos cidadãos, em especial arquitectos em acções individualizadas, são de facto constantes e de uma surpreendente variedade de escalas. Porém todos sabemos como as mais recorrentes imagens de paisagem urbana são resultado de tudo isso e não a cristalização de um fantástico ou inspirado pecado/esboço original.

Sabemos também como as marcas originais sobre o território, sejam elas produzidas de forma orgânica ou planeada, em fundação ou extensão, perduram como vincos matriciais da espacialidade urbana. De facto, em Urbanismo a caracterização da forma - o remate consiste na relação da cidade com a sua principal infra-estrutura, o território. Mas uma vez mais como na Arquitectura, se o carácter se concentra nos remates, já a poética se espraia pela penumbra formal das massas e espaços intersticiais. Não foi por acaso que a adopção quase extrema pelo modernismo da máxima de Luis Sullivan "take care of the terminals and then the rest will take care of itself" produziu os resultados críticos que todos sabemos, quer na arquitectura, quer no urbanismo.

> Há pois uma ecologia da forma e do desenho urbanos, uma lógica cultural e evolutiva que não pode prescindir de utopias e de vanguardas, mas também exige bom senso e, ainda mais, capacidade de análise e de compreensão de tudo o que nos rodeia. Interpretar e questionar a própria evolução é uma acção vital para a humanidade. Como parte dos agentes da urbanidade, o arquitecto deverá continuar a usar o desenho como o seu instrumento específico, mas não poderá continuar a deixar em outras mãos o exclusivo do conhecimento sensível das mais diversas realidades e alhear da sua disciplina o conhecimento da cidade e da sociedade que lhe poderá ser proporcionado por outros. Afinal o desenho como desígnio não resulta de actos místicos ou iniciáticos, mas tão só de uma metodologia e disciplina de síntese. Síntese que, no entanto, nem deve enveredar pelos trilhos da demagogia, nem enfiar a racionalidade na areia ou, melhor, deve evitar continuar a pretender enfiar a Suiça (paisagem, país ou pastelaria) na Betesga. 